\title{
Defected Ground Structure Based Two Element Microstrip Antenna Array with Reduced Mutual Coupling
}

\author{
D. Nataraj, G. Karunakar
}

\begin{abstract}
In this paper two element microstrip antenna array with dumbbell shaped defected ground structure (DGS) is on reduction of mutual coupling is presented. The proposed of DGS antenna is simulated by an soft HFSS simulation software. this work is obtain a miniaturized microstrip patch antenna array using DGS for $S$ Band is $2.2 G H z$.Initally the patch antenna array is designed at $C$ band resonates at $5.2 \mathrm{GHz}$ and the proposed of $D G S$ is integrated in the ground plane of patch antenna for size reduction and this miniaturization is at cost of gain antenna and in order to improve the gain of miniaturized radiator. Patch radiator is further modified to radiation properties, so finally the resonance frequency of an initial microstrip antenna array shifts to $3.75 \mathrm{GHz}$ to $7.15 \mathrm{GHz}$ with the gain of $2.92 \mathrm{~dB}$ and its miniaturization performance is up to $63 \%$ and its conventional microstrip is successfully accomplished. The prototype antenna is fabricated with the FR-4 substrate and this technique is validate experimentally and measured results with good agreement as stimulated results.
\end{abstract}

Key Words --- Microstrip Patch Antenna Array, DGS (Defected Ground Structure), Miniaturization.

\section{INTRODUCTION}

In some applications the single element array antenna are unable to meet the radiation pattern or gain of the given requirements and combining a several single antenna elements are in array can give a possible solution. The patch is typically wider than the strip of its shape and dimensions of the antenna because of the simplicity and compatibility of printed circuit technology. It is wide range of microwave applications of satellite and mobile communication. The basic antenna suffers its electrical performance of number of serious drawbacks and it's include very narrow bandwidth, low gain and the excitation of surface waves [2 -5]. The past years, a lot of research has been undertaken to overcome the disadvantages associated with the antennas. The proposed antenna has popular research techniques by researchers to enhance the bandwidth of the antenna should increase the substrate thickness using low dielectric material. By varying incorporating various impedance matching and feeding elements have multi resonators, multi-slot hole coupling using planar parasitic elements etc. The alternate factor which has important factor and its disadvantage its performance of gain of antenna its shows directional property of antenna by enlarging the single element of antenna it leads to more directive array antenna .Its many applications shows the design of antenna with directive gain for its meet a condition of long distance communication the alternative source of the single element its enlarge the length

Revised Version Manuscript Received on August 14, 2019.

D. Nataraj, Associate Professor, ECE Dept., Pragati Engineering College, Surampalem A.P, India.

Dr. G. Karunakar , Associate Professor, ECE Dept., GIT, GITAM Deemed University, Visakhapatnam, A.P, India. of dimension of antenna without necessarily increased its size of individual single element .It is in the form of assembly of radiating elements in an electrical and geometrical configurations these antenna has be different formed by multi elements and its referred array by is communication system by its enhance the performance of the antenna like gain, directivity scanning the beam of the antenna system and some other functions. Some are difficult at single antenna which tends to performance of such antenna tends to drop due to the strong mutual interaction between the antenna elements and therefore the microstrip antenna design has mutual coupling between radiating elements is an important factor has to be considered the miniaturization of antenna has become more and more important due to the increasing demand for small antenna as the rapid development in wireless communication. They are many efforts have been made in order to achieve the size of reduction like using Planar Inverted F Antenna structure (PIFA) or that is using as dielectric substrate of high permittivity, DMS (Defected Microstrip Structure)and DGS are combination of them. for different applications of microstrip patch antenna is employed with DGS has instance, cross polarization, mutual coupling reduction in antenna arrays and harmonic suppression over the DGS it widely used in the development of miniaturized antennas.

2 Antenna array radiation pattern and array factor The antenna elements can be arranged in one or two dimensional antenna array. The one dimensional antenna array can be very simplicity they exhibits a specific radiation pattern changes for several antenna elements that are combined in array it is called array factor .By this array factor. the radiation pattern has overall it determined as array factor in the antenna element and over all radiation pattern results are in directivity and gain has linked through efficiency with in directivity and gain are equal efficiency is $100 \%$.

\section{DESIGN OF TWO ELEMENT DGS ARRAY ANTENNA}

The structure of two element array as shown in fig. the elements is composed of patch, ground plane, substrate and the feeding line the performance of array patch antenna depends on their frequency, radiation efficiency, directivity, gain, return loss and some other parameters. The designed of microstrip patch antenna was width, length, of their mathematical expressions.

Where $\mathrm{c}=3^{*} 10^{8}, \varepsilon_{\mathrm{r}}=4.4, \mathrm{f}_{\mathrm{o}}=3.75 \mathrm{GHz}$ Width of the patch is given by

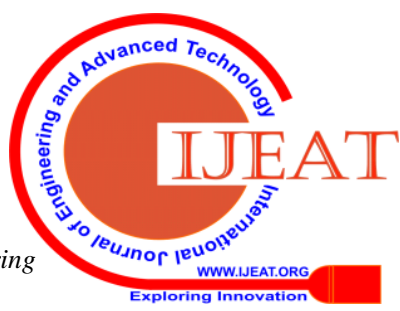




$$
W=\frac{c}{2 f_{r} * \sqrt{\epsilon_{e f f}+\frac{1}{2}}}
$$

Length of the patch is given by

$$
L=\frac{c}{2 f_{r}\left(\epsilon_{e f f}\right)^{\frac{1}{2}}}-2 \Delta l
$$

Effective Dielectric Constant $\left(\varepsilon_{\mathrm{r}}\right)$ is :

$$
\begin{gathered}
\epsilon_{e f f}=\frac{\epsilon_{r}-1}{2}(1+12 h)^{\frac{-1}{2}}+\frac{\epsilon_{r}+1}{2} \\
\text { and } \Delta l \text { can be given as } \\
\Delta l=0.412 h\left(\frac{0.262 h+\left(\frac{w}{h}\right)}{0.813 h+\left(\frac{w}{h}\right)}\right)\left(\frac{\epsilon_{e f f}+0.3}{\epsilon_{e f f}+0.28}\right)
\end{gathered}
$$

Microstrip Patch Length can be calculated

$$
L s=\frac{0.42 * c}{f_{r} *\left(\epsilon_{e f f}\right)^{\frac{1}{2}}}
$$

The Ground Plane width can be calculated

$$
W_{g}=\frac{1.38 * c}{f_{r} *\left(\epsilon_{e f f}\right)^{\frac{1}{2}}}
$$

The Ground Plane Length can be calculated

$$
L_{g}=\frac{0.36 * c}{f_{r} *\left(\epsilon_{e f f}\right)^{\frac{1}{2}}}
$$

Resonant frequency is

$$
f_{r}=3+\frac{2}{\left(\epsilon_{e f f}\right)^{\frac{1}{2}}}\left[\frac{21}{L_{s}}+\frac{65}{W_{g}}+\frac{18}{L_{g}}-3\right] \text { (7) }
$$

\section{SIMULATION OF TWO ELEMENT DGS ARRAY ANTENNA}

\section{Antenna Simulation Using HFSS}

The microstrip patch antenna was designed by using HFSS simulator and performance of antenna has studied and observed .comparing the return loss, VSWR and gain. The two element array is simulated by HFSS and the design of corresponding figure $1 \& 2$ as shown in below the return loss, VSWR and gain results are observed at $3.75 \mathrm{GHz}$

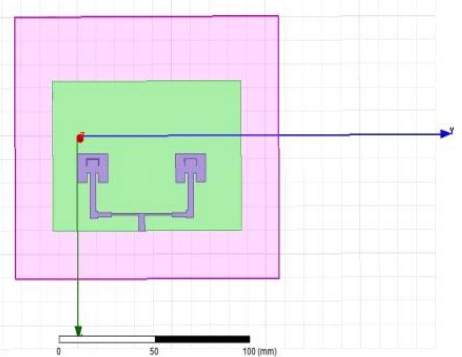

Fig. 1: Front view structure of the simulated two elements antenna array

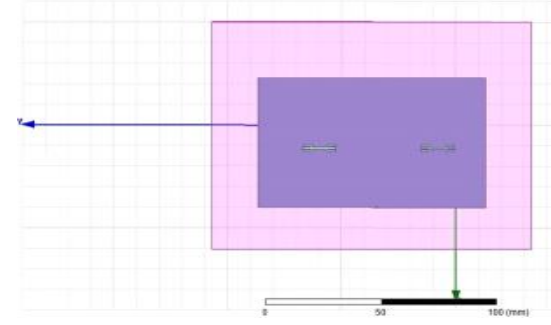

Fig. 2: Back view structure of the simulated two elements antenna array

\section{RESULTS}

i) Simulation Results

\section{1) Return Loss}

The Return Loss of microstrip patch antenna of two element antenna array is as shown in figure 3 and from this figure it is observed that the return loss as $-22.74 \mathrm{~dB}$ at $3.75 \mathrm{GHz}$ and $-10.19 \mathrm{~dB}$ at $7.15 \mathrm{GHz}$.

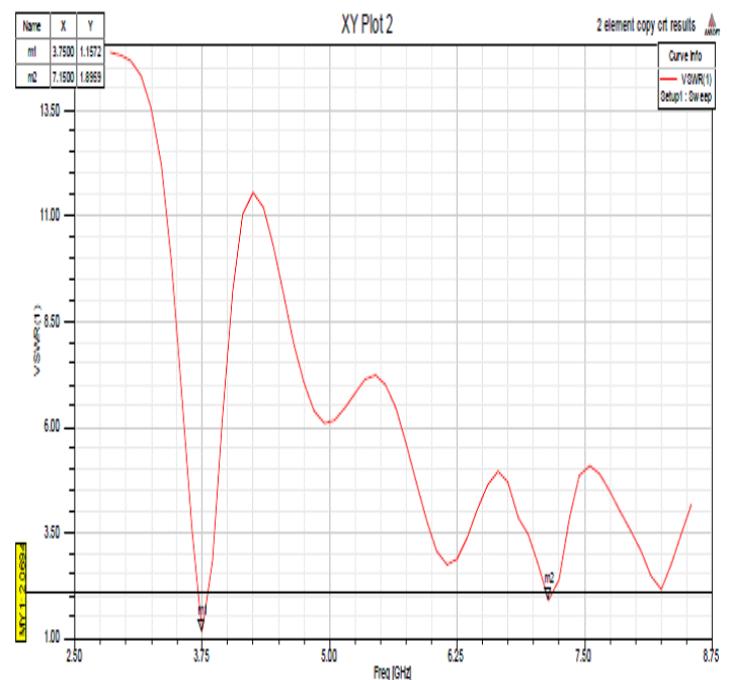

Fig. 3: Return Loss for microstrip patch two elements antenna array

\section{2) VSWR}

The impedance of the VSWR is to measure the between transmitter of the antenna. The simulations results of the microstrip patch antenna with -E-shape DGS as shown in fig 4.The values are observed by practical VSWR at $3.75 \mathrm{GHz}$ is 1.15 at $7.15 \mathrm{GHz}$ is 1.89 and at range below $-10 \mathrm{~dB}$ and return loss is also below VSWR $=2$

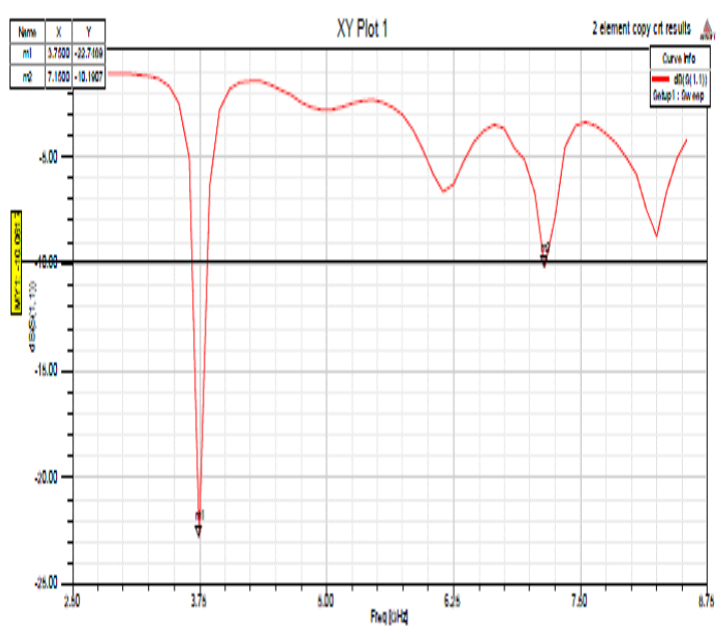

Fig. 4: VSWR for microstrip patch two elements antenna array

\section{3) 3-D Gain}

The two element antenna array was designed by HFSS and gain is nothing but the power transmitted per unit solid angle. As shown in fig. 5 the gain is observed in $2.92 \mathrm{~dB}$. For much application the gain of antenna is should be more than $3 \mathrm{~dB}$.

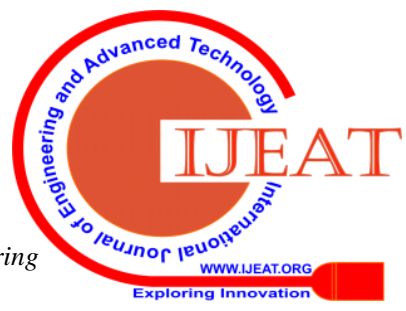




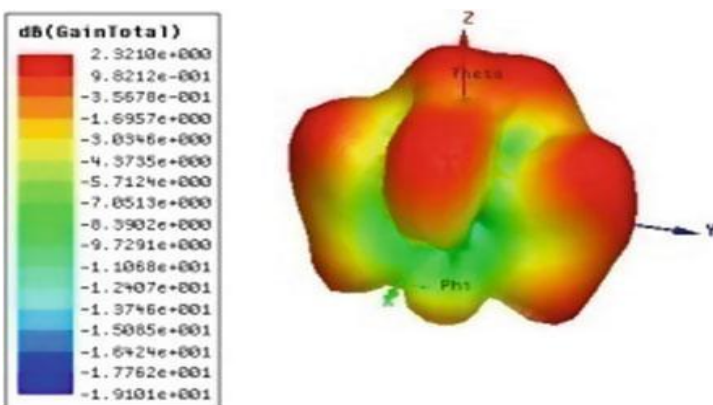

Fig. 5: 3-D Gain for two elements antenna array

\section{4) Radiation Pattern}

It defines the variations of the power radiated by the antenna in the function of direction away from the antenna far filled antenna can be observed in the function of poor variation in arrival angle. The radiation pattern of two element array can observed in the fig. 6
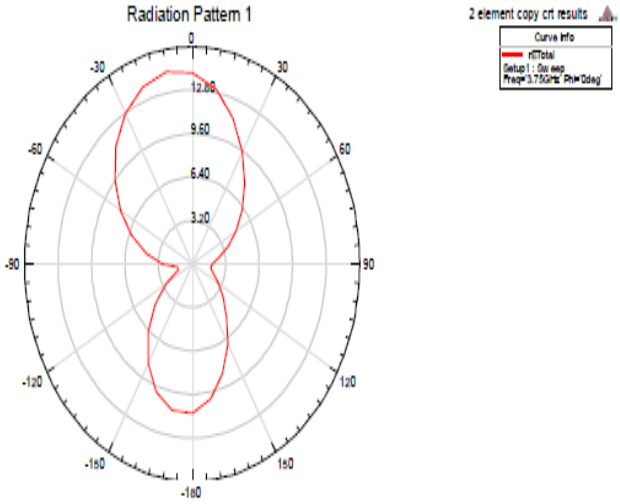

Fig. 6: The radiation pattern of two elements antenna array

\section{SMITH CHART}

The smith chart is a tool which it represents for solving radio frequency transmission line problems. The value of reflection coefficient is 0 and that VSWR is 1 in the unmatched impedance condition therefore all the transmission lines problems are to be match the impedance line of the total load. The polar plot of the reflection coefficient $\mathrm{K}$ can be expressed in the form of normalized impedance .The smith chart for two element antenna array is observed at figure 7
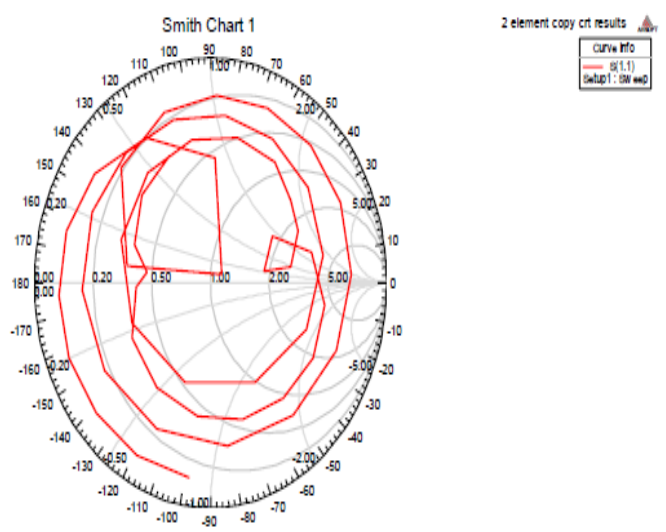

Fig. 7: The smith chart of two elements antenna array

\section{POLARIZATIONS}

Polarization of two element antenna array is observed in figure 8 and 9

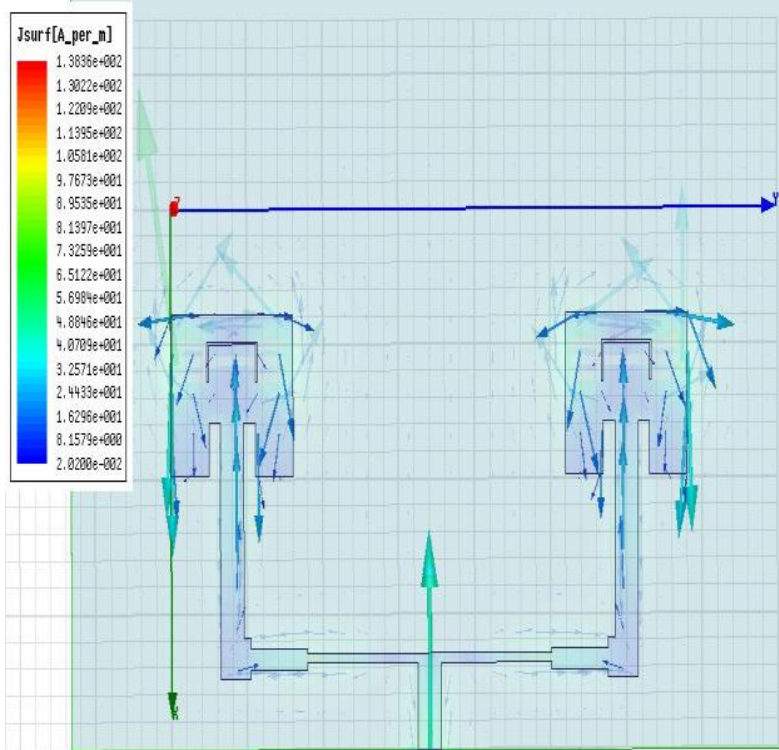

Fig. 8: The polarization front view of two elements antenna array

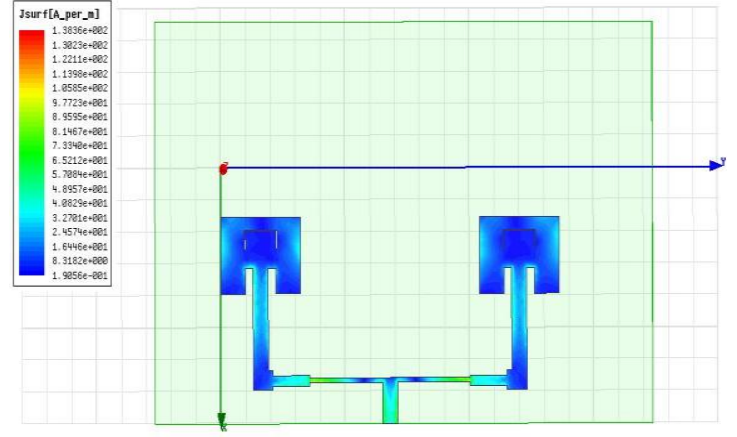

Fig. 9: The polarization back view of two elements antenna array

\section{CURRENT DISTRIBUTIONS \& RESULTS}

Current distribution of front and back view of two element antenna array is observed in the figure 10 and 11

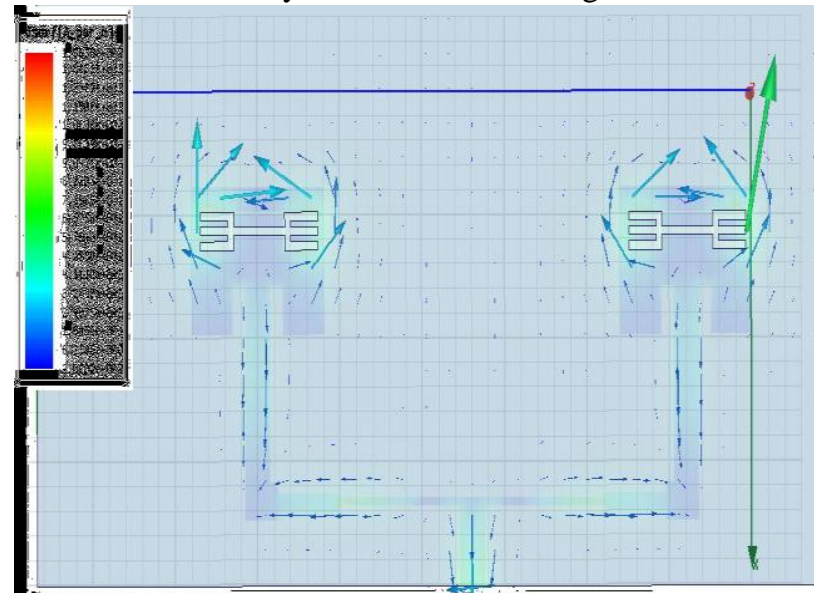

Fig. 10: The current distribution of front view of two elements antenna array 


\section{DEFECTED GROUND STRUCTURE BASED TWO ELEMENT MICROSTRIP ANTENNA ARRAY WITH REDUCED MUTUAL COUPLING}

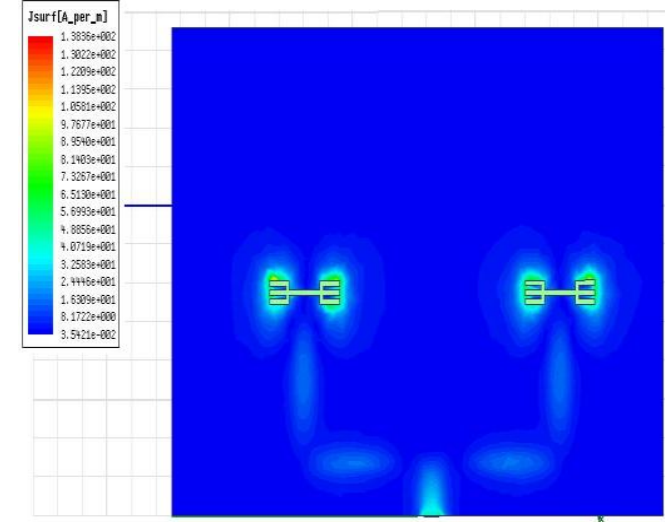

Fig. 11: The current distribution of back view of two elements antenna array

\section{ii) Measured Results}

The 2 element array DGS antenna is met at practical applicable antenna by the all requirements of fabricated to 4 element array by the DGS antenna

Two element DGS array antenna this antenna can be observed and tested in Vector Network Analyzer (E5071C) as shown in figure 12

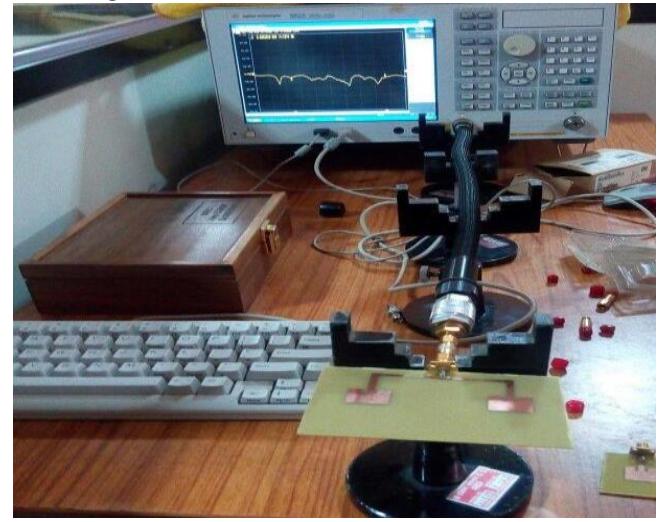

Fig. 12: The experimental setup loss for two element DGS array antenna

\section{1) Return Loss}

The Return Loss for two element DGS array antenna is observed in the figure 13

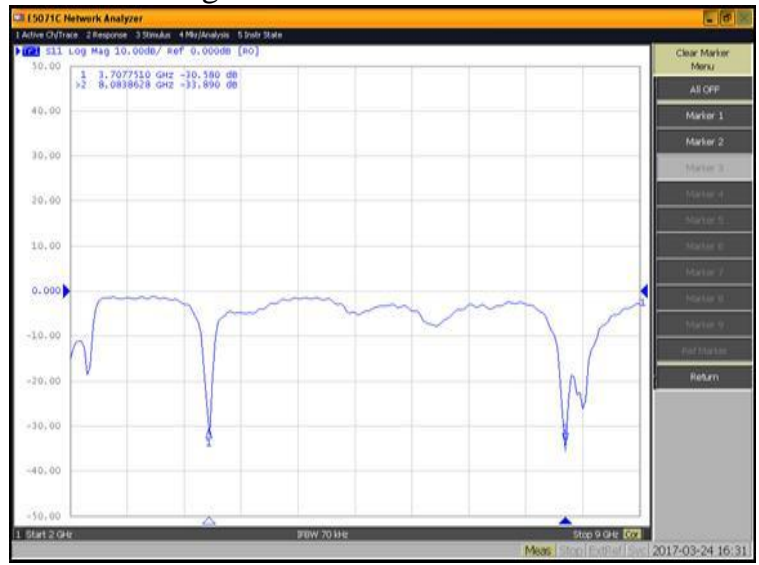

Fig. 13: The measured return loss for two element DGS array antenna

\section{2) VSWR}

SWR for the two element array antenna is shown in figure 14

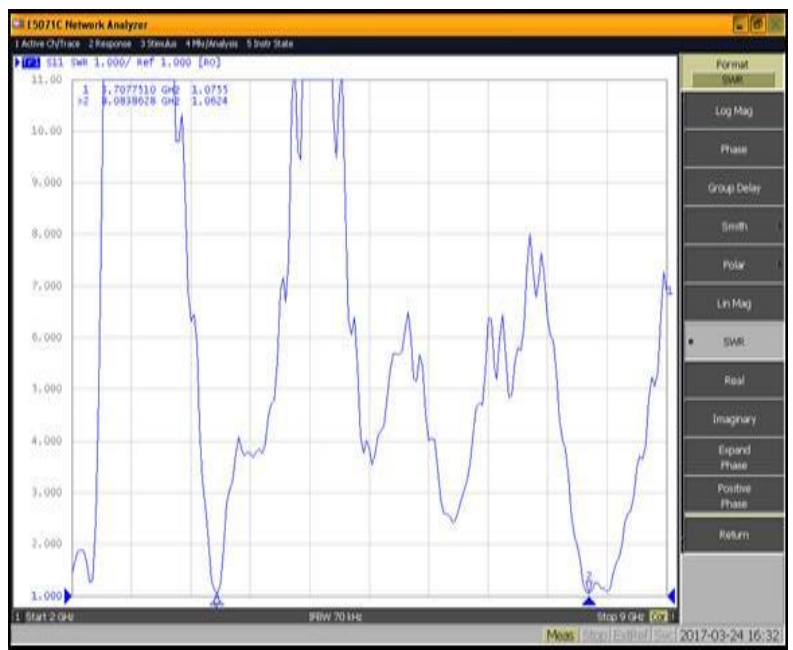

Fig. 14: The measured SWR for two element DGS array antenna

\section{3) Smith Chart}

The smith chart for two element DGS array antenna is observed in figure 15

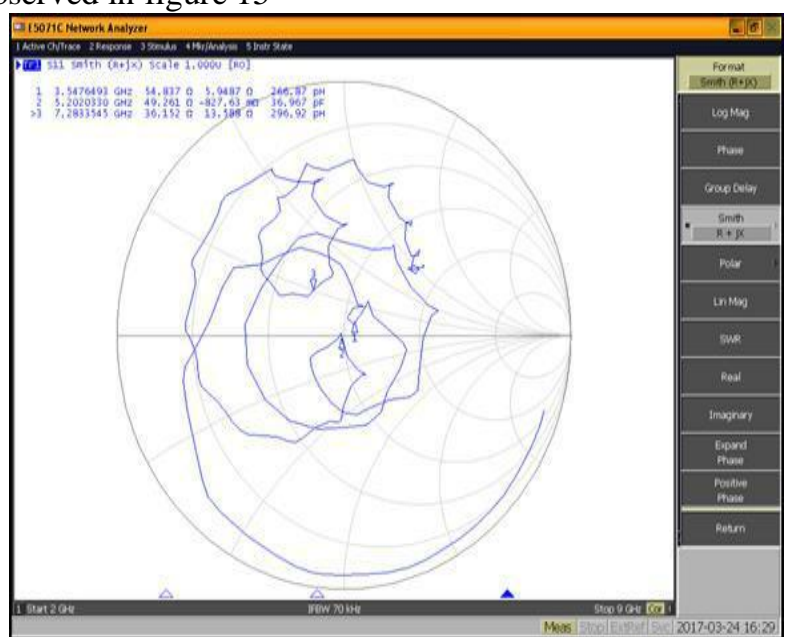

Fig. 15: The smith chart for two element DGS array antenna

Comparison between Simulation and Measured results 2element and 4-element DGS Array Antennas

Table1: Comparison Between 2-element And 4-element DGS Array Antennas.

\begin{tabular}{|l|l|l|l|l|}
\hline Parameter & $\begin{array}{l}\text { Frequenc } \\
\text { y of } \\
\text { operation } \\
\text { (GHz) }\end{array}$ & $\begin{array}{l}\text { Return } \\
\text { loss(dB } \\
\text { ) }\end{array}$ & $\begin{array}{l}\text { VSW } \\
\text { R }\end{array}$ & Gain(dB \\
) & & \\
\hline $\begin{array}{l}\text { 2-Element } \\
\text { (Simulation }\end{array}$ & 3.75 & -22.74 & 1.15 & 2.92 \\
\cline { 2 - 5 } ) & 7.15 & -10.19 & 1.89 & \\
\hline $\begin{array}{l}\text { 2-Element } \\
\text { (Measured) }\end{array}$ & 3.70 & -30.45 & 1.07 & -- \\
\cline { 2 - 5 } & 7.08 & -33.63 & 1.66 & \\
\hline
\end{tabular}

\section{CONCLUSIONS}

The design of the work carried out in a miniaturized microstrip patch antenna array with the DGS. The resonance frequency of the initial stage antenna has $5.7 \mathrm{GHz}$ and its is passed and shifted to $3.75 \mathrm{GHz}$ and after introducing the DGS.

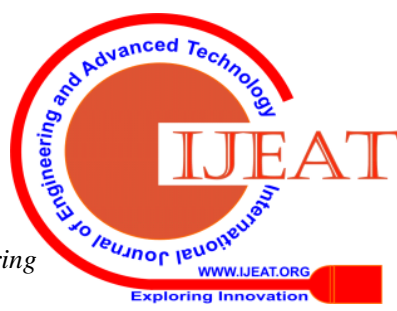


The design of the antenna it reduces to $50 \%$ as compared to conventional band uses and perform better under condition of $\mathrm{Ku}$-band and $\mathrm{Ka}$ band frequency the initiated miniaturization procedure was typical rectangular patch antenna is shaped with array antenna by switch of DGS and gives a reduction of $79 \%$ and its resonance frequency initial antenna without DGS has be shifted to $5.2 \mathrm{GHz}$ to $4.05 \mathrm{GHz}$ resonating at $1.32 \mathrm{~dB}$

The miniaturization procedure initiated with a typical rectangular patch shaped array antenna with DGS gives a size reduction up to $79 \%$ as the resonance frequency of the initial antenna without DGS has been shifted from $5.2 \mathrm{GHz}$ to $2.4 \mathrm{GHz}$ resonating at $-17.86 \mathrm{~dB}$ with the gain of $1.94 \mathrm{~dB}$ and $100 \mathrm{MHz}$ bandwidth. To achieve antenna without much degradation of the performance of the antenna miniaturization without much degradation of antenna performance, further the patch radiator is modified keeping the physical volume of the antenna constant with the same DGS structure to retain its radiation properties which gives a size reduction up to $83 \%$ as the resonance frequency of the initial antenna without DGS has been shifted from $5.2 \mathrm{GHz}$ to $2.2 \mathrm{GHz}$ resonating at $-32.26 \mathrm{~dB}$ with the measured gain of $4.14 \mathrm{~dB}$ and $120 \mathrm{GHz}$ bandwidth. In this way we have been able to reduce the maximum antenna size up to $83 \%$ as compared to conventional.

\section{REFERENCES}

1. D. G. Fang, Antenna theory and microstrip antennas, 1 edition. CRC Press/Taylor \& Franci, p. 311, 2009.

2. A.K. Bhattachar jee, S.R Bhadra, D.R. Pooddar and S.K. Chowdhury, "Equivalence of impedance and radiation properties of square and circular microstrip patch antennas," IEE Proc. 136(Pt, H, 4): pp. 338-342. 1989

3. K. Carver and J. Mink, "Microstrip antenna technology," I EEE Trans. Antennas Propag., vol. 29, no. 1, pp. 2-24, Jan. 1981.

4. A. A. D. Al-sajee and K. A. Hamad, "Improving bandwidth rectangular patch antenna using different thickness of dielectric substrate", ARPN Journal of Engineering and Applied Sciences, vol. 6, no. 4, pp. 16-21, 2011.

5. P. K. Patra, S. S. Pattnaik, S. Devi, C. Vidyasgar, G. V. R. S. Sastry \& K. M. Bakward, "New bandwidth enhancement and mulitresonance technique for microstrip patch antenna", Microw Opt Technolo Lett (USA), 1162 50, 2008.

6. H. S. Wi, S. Y. Lee \& J. G. Yook, “ Wideband microstrip patch antenna with U-shaped parasitic elements", IEEE Trans Antennas Progpag (USA), 1196, 5 (2007).

7. C. A. Balanis, "Antenna Theory, Analysis and Design,” John Wiley \& Sons, New York, 1997. 73

8. F. Yang and Y. R. Sami, "Micorstrip antennas integrated with Electromagnetic Band Gap (EGB) structures: a low mutual coupling design for array applications," IEEE Trans. Antennas Propag., vol. 51, no. 10, pp. 2936-2946, Oct. 2003.
9. Park, J. S., J. H. Kim, J. H. Lee, S. H. Kim, and S. H. Myung, "A novel equivalent circuit and modeling method for defected ground structure and its application to optimization of a DGS lowpass filter," IEEE MTT-S Int. Dig., 417-420, 2002.

10. Arya, A. K., M. V. Kartikeyan, and A. Patnaik, "Efficiency enhancement of microstrip patch antennas with defected ground structure," Proc. IEEE Recent Advanced in Microwave Theory and Applications (MICROWAVE-08), 729-731, Nov. 2008.

11. Nashaat, D., H. A. Elsade, E. Abdallah, H. Elhenawy, and M. F. Iskandar, "Multiband and miniaturized inset feed microstrip patch antenna using multiple spiral-shaped defectground structure (DGS)," IEEE Antennas and Propagation Society International Symposium, 2009, APSURSI'09, 1-4, Jun. 1-5, 2009.

12. .Elsheakh, D. M., H. A. Elsadek, E. A.-F Abdallah, H. M. Elhenawy, and M. F.Iskander, "Miniaturized and multiband operations of inset feed microstrip patch antenna by using novel shape of defected ground structure (DGS) in wireless app lications," PIERS Proceeding, 1082-1086,Moscow, Russia, Aug. 18-21, 2009.

13. Liu, J.,W.-Y. Yin, and S. He, "A new defected ground structure and its application for miniaturized switchable antenna," Progress In Electromagnetic Research, Vol. 107, 115- 128, 2010.

14. Zulkifli, F. Y., E. T. Rahardjo, and D. Hartanto, "Mutual coupling reduction using dumbbell defected ground structure for multiband microstrip antenna array," Progress In Electromagnetics Research Letters, Vol. 13, 2940, 2010.

15. Arya, A. K., A. Patnaik, and M. V. Kartikeyan, "Microstrip patch antenna with skew-F shaped DGS for dual band operation," Progress In Electromagnetics Research M, Vol. 19, 147-160, 2011.

16. Chakraborty, M., B. Rana, P. P. Sarkar, and A. Das, "Size reduction of microstrip antenna with slots and defected ground structure," International Journal of Electronics Engineering, Vol. 4,No. 1, 61-64, 2012.

17. Kapoor, S. and D. Parkash, "Miniaturized triple band microstrip patch antenna with defected ground structure for wireless communication applications," International Journal of Computer Applications, Vol. 57, No. 7, ISSN: 0975-8887, Nov. 2012.

18. Boutejdar, A., "Compensating for DGS filter loss," Microwave and Communication Engineering, Magdeburg, Germany, 2012. 
19. T.K. Lo, Y. Hwang, Microstrip antennas of high permittivity for personal communication, in: 1997 Asia Pacific Microwave Conference, 1997, pp. 253-256.

20. J.A. Tirado-Mendez, M.A. Peyrot-Solis, H. Jardon-Aguilar, E.A. Andrade- Gonzalez, M. Reyes-Ayala, Applications of novel defected Microstrip structure (DMS) in planar passive circuits, in: Proceedings of the 10th WSEAS International Conference on CIRCUITS, Vouliagmeni, Athens, Greece, July 10-12, 2006, pp. 336-369.

21. M. Chakraborty, B. Rana, P.P. Sarkar, A. Das, Size reduction of Microstrip antenna with slots and defected ground structure, Int. J. Electron. Eng. 4 (1) (2012) 61-64.

22. Hanae Elftouhl, Naima A. Touhami, Mohamed Aghoutane, Miniaturized microstrip patch antenna with defected ground structure, Prog. Electromagnet. Res., C 55 (2014) 25-33. 